\title{
Apontamentos para a arquitetura hospitalar no Brasil: entre o tradicional e o moderno*
}

\section{Notes on hospital architecture in Brazil: between the traditional and the modern}

\section{Renato Gama-Rosa Costa}

Arquiteto e urbanista do Departamento de Patrimônio Histórico/ Casa de Oswaldo Cruz/Fundação Oswaldo Cruz.

$$
\text { Av. Brasil, } 4.365
$$

21040-900 - Rio de Janeiro - RJ - Brasil

rgrc@coc.fiocruz.br

Recebido para publicação em junho de 2010.

Aprovado para publicação em janeiro de 2011.

COSTA, Renato Gama-Rosa.

Apontamentos para a arquitetura hospitalar no Brasil: entre o tradicional e o moderno. História, Ciências, Saúde Manguinhos, Rio de Janeiro, v.18, supl.1, dez.2011, p.53-66.

\section{Resumo}

Aponta desafios para aprofundar a relação nem sempre evidente entre história da assistência em saúde e arquitetura, expressa de forma mais clara na construção dos espaços para tratamento médico, sobretudo os hospitais e os sanatórios. Estamos diante da constituição de um campo de conhecimento pouco explorado, que vem animando pesquisadores das ciências humanas e sociais aplicadas no Brasil, sobretudo nas últimas décadas.

Palavras-chave: instituições de saúde; arquitetura hospitalar; assistência; história; Brasil.

\section{Abstract}

The relationship between the history of health assistance and architecture is not always obvious. The article points to some challenges in investigating this relation, which is most readily visible in the construction of medical facilities, especially hospitals and sanitariums. In Brazil, this fledgling field has begun drawing the attention of researchers from the applied human and social sciences, especially in more recent decades.

Keywords: healthcare facilities; hospital architecture; assistance; history; Brazil. 
$\mathrm{A}$ s discussões sobre temas que agregam história da assistência em saúde e arquitetura revelam-se ainda muito promissoras e estão longe de ser esgotadas. Neste artigo, procuro contribuir com reflexões recentes de historiadores e arquitetos sobre a história das instituições de saúde e assistência, apresentando uma perspectiva transversal da arquitetura para a saúde.

Entre os trabalhos mais representativos publicados sobre o tema - e que assim se mantêm como referência -, podemos citar o estudo pioneiro de Jaime Benchimol (1990), sobre os paradigmas da arquitetura hospitalar no início do século; o de Lauro Carlos Miquelin (1992), único trabalho brasileiro a introduzir o tema das tipologias arquitetônicas para a saúde; e o de Tânia Bittencourt (2000), sobre a arquitetura sanatorial de São José dos Campos. Da década de 2000, destaca-se o artigo de Gisele Sanglard e Renato da Gama-Rosa Costa (2004) sobre o Hospital Gaffrée e Guinle e seu arquiteto; as investigações de Toledo (2006, 2008); os trabalhos de Fabio Bitencourt em comemoração aos sessenta anos do Hospital dos Servidores do Estado (2007) e dos noventa anos do Instituto Vital Brazil (2009); e o estudo de Ângela Pôrto (2008), em que o tema da arquitetura hospitalar aparece com destaque.

Desde 2007 a Casa de Oswaldo Cruz coordena uma rede cujo objetivo é inventariar instituições de saúde construídas entre 1808 e 1958, privilegiando a investigação sobre sua história e seu patrimônio documental e arquitetônico. Em 2008 foram publicados dois inventários: o do Rio de Janeiro (Pôrto, 2008) e o de Porto Alegre (Weber, Serres, 2008). Prevê-se, em médio prazo, a publicação dos inventários de outras capitais: Salvador, São Paulo, Belo Horizonte, Florianópolis, Goiânia, Belém, Curitiba, Manaus e Recife.

Em termos de investigação histórica sobre a tipologia da arquitetura hospitalar, sobressai o trabalho de Pevsner (1997), com capítulo específico sobre hospitais, e o de Mignot (1983), com capítulo dedicado aos hospitais e às prisões. Entretanto, as obras que ainda servem de estudos clássicos para o tema são as de Foucault (1979), com capítulo dedicado ao nascimento do hospital, e a publicação coordenada por ele, Les machines a guèrir, também de 1979, sobre as origens do hospital moderno. Ainda no plano internacional, grupos constituídos principalmente na França vêm-se destacando nessa questão ao associar a história com a preocupação patrimonial, a exemplo do livro de Jean-Bernard Cremnitzer (2005), Architecture et santé, sobre os sanatórios franceses, e o colóquio organizado em 2004 pelo Docomomo Internacional ${ }^{1}$, Histoire et Réhabilitation des Sanatoriums en Europe, cujos trabalhos foram publicados em número especial de seu jornal (Cremnitzer, Toulier, 2004).

Este artigo explora o tema a partir de exemplos brasileiros. Enfocando a complexidade que passa a envolver as estruturas de saúde, especialmente depois do nascimento do hospital moderno, em finais do século XVIII, conforme relata Michel Foucault (1979), até os hospitais tecnológicos projetados na década de 1950. Na concepção do hospital moderno, segundo esse pesquisador, nenhuma teoria médica por si mesma seria suficiente para definir um programa hospitalar. Com base nos inquéritos realizados em torno de 1780, sobretudo o chefiado por Jacques Tenon, para a reconstrução do Hôtel-Dieu de Paris, destruído por um incêndio em 1772, Foucault afirma que nenhum plano arquitetônico abstrato poderia dar a fórmula do bom hospital. Pelo contrário, o projeto de arquitetura se revela um objeto complexo, do qual mal se conhecem efeitos e consequências que agem sobre as doenças e 
são capazes de agravá-las, multiplicá-las ou atenuá-las. Somente um inquérito empírico sobre esse novo objeto - o hospital - seria capaz de dar ideia de um novo programa de construção de hospitais: "ele agora faz parte de um fato médico-hospitalar que se deve estudar como são estudados os climas, as doenças etc." (p.100). ${ }^{2}$

Foucault, na introdução de Machines a guérir, observa que entre 1772 e $1788^{3}$ foram realizados mais de duzentos planos de reforma e mais de cinquenta projetos de arquitetura com a validação da Academia Real de Ciências de Paris, com o objetivo de fazer do hospital uma máquina de guerra (Foucault et al., 1979). Dizia-se, na época, que um dos motivos para a alta mortalidade verificada até antes do incêndio do Hôtel-Dieu era a falta de troca do ar viciado combinada com a superlotação - que levava à acomodação de até três pacientes por leito, sem distinção de sexo, idade ou tipo de doença. Tenon e Maxime du Camp diriam em seus relatórios: "Pobres jovens e idosos, hábeis ou inválidos, loucos, imbecis, epiléticos, cegos e todo o tipo de incuráveis", vivendo "pêle-mêle na mais assustadora promiscuidade" (citado em Pevsner, 1997, p.145). Para Jean-Baptiste Le Roy, também autor de um desses inquéritos, o pátio, cuja intenção era fazer a tão desejada ventilação dos quartos, se apresentava como uma "máquina para curar o doente" (citado em Pevsner, 1997, p.151). Para Tenon, o importante era estabelecer uma distância saudável entre os leitos e separar as atividades, como cirurgia e expurgo de material sujo e dejetos.

No Brasil, o hospital moderno nasceu na passagem do modelo religioso para o modelo pavilhonar, em meados do século XIX, e procurava acompanhar a trajetória dessas construções na Europa, regidas primeiramente sob o princípio da construção em claustro, mas que sofreram profundas transformações depois do higienismo e ainda mais com os trabalhos de Louis Pasteur e a bacteriologia. Durante as primeiras décadas do século XX, os projetos hospitalares estiveram sob a influência dessas ciências, porém atentos ao modelo que se consolidava nos EUA - a construção em bloco único, que é a tônica do modelo hospitalar até hoje.

Para acompanhar essa trajetória da arquitetura hospitalar no Brasil, desde o modelo religioso, passando pelo sistema de pavilhões e chegando primeiramente ao monobloco de transição e depois até o monobloco modernista, estudaremos alguns exemplares que Venâncio (2011) e Monteiro (2011) abordam em artigos deste mesmo suplemento de História, Ciências, Saúde - Manguinhos, colhidos nos inventários realizados pelos coordenadores regionais da Rede Brasil, no âmbito do Inventário do Patrimônio Cultural da Saúde - Bens Edificados e Acervos.

\section{O modelo hospitalar religioso}

Da Bahia, a mais antiga de nossas capitais contempladas no Inventário, temos o exemplo do Hospital São Cristóvão, criado e administrado pela Santa Casa de Misericórdia durante toda a sua existência, ou seja, de 1549 a 1893, quando foi inaugurado o novo Hospital da Misericórdia - o Santa Isabel. A pesquisa organizada por Renilda Barreto (2011) acerca desse hospital revela o perfil de sua população enferma com base em condições jurídicas, idade, gênero e ocupação, no período em que se discutia a necessidade de modernizar o espaço hospitalar à luz dos preceitos das ciências médicas, em particular o higienismo, na 
primeira metade do século XIX. Era preciso superar divisões tradicionais entre médicos e cirurgiões e o regime, que contava com mão de obra escrava para a realização dos serviços mais pesados e menos qualificados:

O Hospital São Cristóvão foi um dos braços misericordiosos da Santa Casa baiana, encarregado de oferecer cuidados médicos à população residente ou flutuante. Os registros da irmandade demonstram que ela prestou assistência médico-cirúrgica aos presos, soldados, estrangeiros, marinheiros, alienados, mendigos e escravos. Este nosocômio foi o único da cidade de Salvador a abrir suas portas para todos os indivíduos, independentemente do estatuto jurídico, matrimonial, étnico e econômico (Barreto, 2011).

Entre os assalariados, uma hierarquia mantinha a diferença de vencimentos entre médicos e cirurgiões, estes vistos como um ramo inferior da medicina. A hierarquia também ocorria entre administradores, facultativos e porteiros e entre enfermeiros. Estes últimos deveriam, ao menos, saber ler e escrever para poder entender as receitas preparadas pelos médicos, o que podia representar, de modo sutil, uma diferenciação de status na classe.

De acordo com Barreto (2011), a população enferma do hospital era composta, na sua maioria, por homens brancos e livres, de extrato mediano da sociedade e com ocupação definida, ou seja, um perfil divergente do apresentado pela historiografia. O Hospital São Cristóvão atendia majoritariamente brancos europeus, a população mestiça de Salvador e um reduzido número de escravos.

Entre os indivíduos que frequentavam as enfermarias do Hospital São Cristóvão, os homens brancos, de ascendência europeia e com ocupação definida eram maioria. O mesmo não se pode afirmar em relação ao público feminino: a maioria das mulheres que foram tratadas no Hospital São Cristóvão era formada por mestiças oriundas de Salvador e de sua circunvizinhança. As enfermarias masculinas ficavam nos fundos do edifício, ao passo que as mulheres ocupavam uma única enfermaria na catacumba, localizada no subsolo, que durante certo tempo funcionou como ossuário.

Conforme inventário registrado no processo de tombamento da igreja pertencente à Santa Casa de Misericórdia, realizado pelo Instituto do Patrimônio Histórico e Artístico Nacional (Iphan), o primeiro hospital e a capela foram "edificados, com recursos obtidos pelas doações dos colonos, em terreno doado por Tomé de Souza. No início do séc. XVII, uma edificação mais sólida, em pedra e cal, substitui aquela primitiva. O conjunto arquitetônico possui tipologia tipicamente conventual. A Igreja determina o eixo da composição, ladeado por dois pátios que distinguiam as atividades administrativas das do hospital" (Barreto, 2011).

A cisterna que abastecia o hospital contava com captação própria de água, e seu esgoto seguia igualmente separado dos demais, para evitar a contaminação de outras fontes de água da cidade de Salvador. Para Pevsner (1997), esse sistema que permitia a captação de água por cisterna e o escoamento das águas usadas, juntamente com a instalação de lavatórios para cada leito, usado de forma exemplar no Ospedale Maggiori (1456). Esse hospital milanês tornou-se um dos principais exemplares de hospital cruciforme, tipologia hospitalar que predominou do século $\mathrm{XV}$ até o surgimento dos hospitais pavilhonares, no século XVIII. 
A primeira tentativa de melhoria do espaço cruciforme, tido como insalubre na maioria dos casos, foi feita a partir de inventários realizados na segunda metade do século XVIII - dos quais o maior representante é o chefiado por Tenon -, que levariam à criação de hospitais regidos pelo higienismo, num primeiro momento, e culminariam nos hospitais pavilhonares cem anos depois, com Tollet. A diferenciação arquitetônica entre esses dois modelos pode ser resumida na sua forma. Enquanto o primeiro adotava enfermarias presas a um corpo central, apresentando plantas de diversas composições (em X, em pente, radial, duplo E, H etc.), o segundo tornou as enfermarias de fato independentes, que passaram a constituir um corpo isolado da construção principal, sem contato algum, nem mesmo por meio de passagens subterrâneas. O primeiro tipo, identificado como higienista pela Assistance Publique Hôpitaux de Paris - a arquitetura ventilada de finais do século XVIII, como essa instituição preferia denominar -, serviria de referência para diversos hospitais construídos no Brasil entre as décadas de 1920 e 1950, antes da consolidação do monobloco modernista, como veremos.

\section{O modelo pavilhonar e de isolamento}

O texto de Ana Venâncio (2011) traz importantes contribuições para a análise dos hospitais construídos conforme o princípio de organização em pavilhões isolados. A autora analisa detalhadamente a organização e estruturação dos hospitais de assistência psiquiátrica, por meio das tipologias das colônias agrícolas e dos hospitais-colônias, e toma como exemplo a Colônia Juliano Moreira, criada em 1924. O estudo permite conhecer melhor a lógica relacionada aos hospitais de isolamento construídos na região de Jacarepaguá, no Rio de Janeiro. Sobretudo em relação aos doentes mentais, pela perspectiva psiquiátrica, a proposta do isolamento foi prontamente associada à vida rural, longe das cidades, o que proporcionava clima ameno e melhor dedicação ao trabalho agrícola. Jacarepaguá - chamado na época de Sertão Carioca - era visto como exemplar de tal finalidade. De acordo com Venâncio, a Colônia Juliano Moreira exemplifica dois momentos da psiquiatria no Brasil, pois foi criada como colônia agrícola, em referência a uma concepção de finais do século XIX, mas se tornaria paradigmática para a moderna assistência psiquiátrica implan-tada nas décadas de 1930 e 1940, o hospital-colônia.

A autora observa esses distintos momentos, pela perspectiva da arquitetura e do urbanismo. Em Jacarepaguá instaralam-se outras unidades de saúde, como as destinadas ao tratamento de tuberculosos (Hospital Santa Maria e Sanatório de Curicica), e de hansenianos (Colônia Curupaiti), com infraestruturas urbanas e arquiteturas muito semelhantes, em especial as da Juliano Moreira e de Curupaiti.

Venâncio (2011) recolhe dados que permitem acompanhar o discurso da proposta médica e urbana para a colônia. O antigo Hospital Psiquiátrico Pedro II, mesmo com as reformas arquitetônicas de 1903 - a cargo do próprio Juliano Moreira, seu diretor então -, já não atendia a modernização da psiquiatria. Por outro lado, as colônias agrícolas seriam excelente meio de assistência aos doentes mentais, e a assistência familiar ao doente contribuía também para a sua recuperação. Nesse sentido, as reformas nas instituições da Ilha do Governador tampouco resolveriam; era necessário construir uma nova colônia. 
Buscou-se um local 'conveniente' para a nova colônia, que pudesse aliar o trabalho agrícola e a assistência familiar no tratamento do doente mental. Foram escolhidas as terras do Engenho Novo, com matas, vargens, rios, cachoeiras, represa e benfeitorias, ou seja, casas de antiga fazenda, um aqueduto que facilitasse a captação de água e uma igreja. O terreno foi adquirido em 1918 e nele foram construídos 15 pavilhões, em 1921, mais refeitório, cozinha, lavanderia, farmácia e enfermarias. Também foram feitas reformas nas instalações existentes.

A disposição dos pavilhões buscava conforto, higiene, aeração e insolação dos ambientes de cura, aproveitando-se a proximidade dos rios, as áreas ajardinadas e a topografia do terreno, conforme o projeto dos hospitais pavilhonares. A arquitetura buscava reproduzir um ambiente familiar, expresso por um 'aspecto rústico', 'de casas comuns', que, segundo o arquiteto Francisco de Paula Ramos de Azevedo (1851-1928) - autor de diversos projetos em São Paulo para instituições de saúde, conformes à concepção do sistema em pavilhões -, seguia, em 1895, a "prescrição dos modernos alienistas" (cf. Wolff de Carvalho, 2000). Juliano Moreira era certamente um adepto dessa concepção (Figura 1).

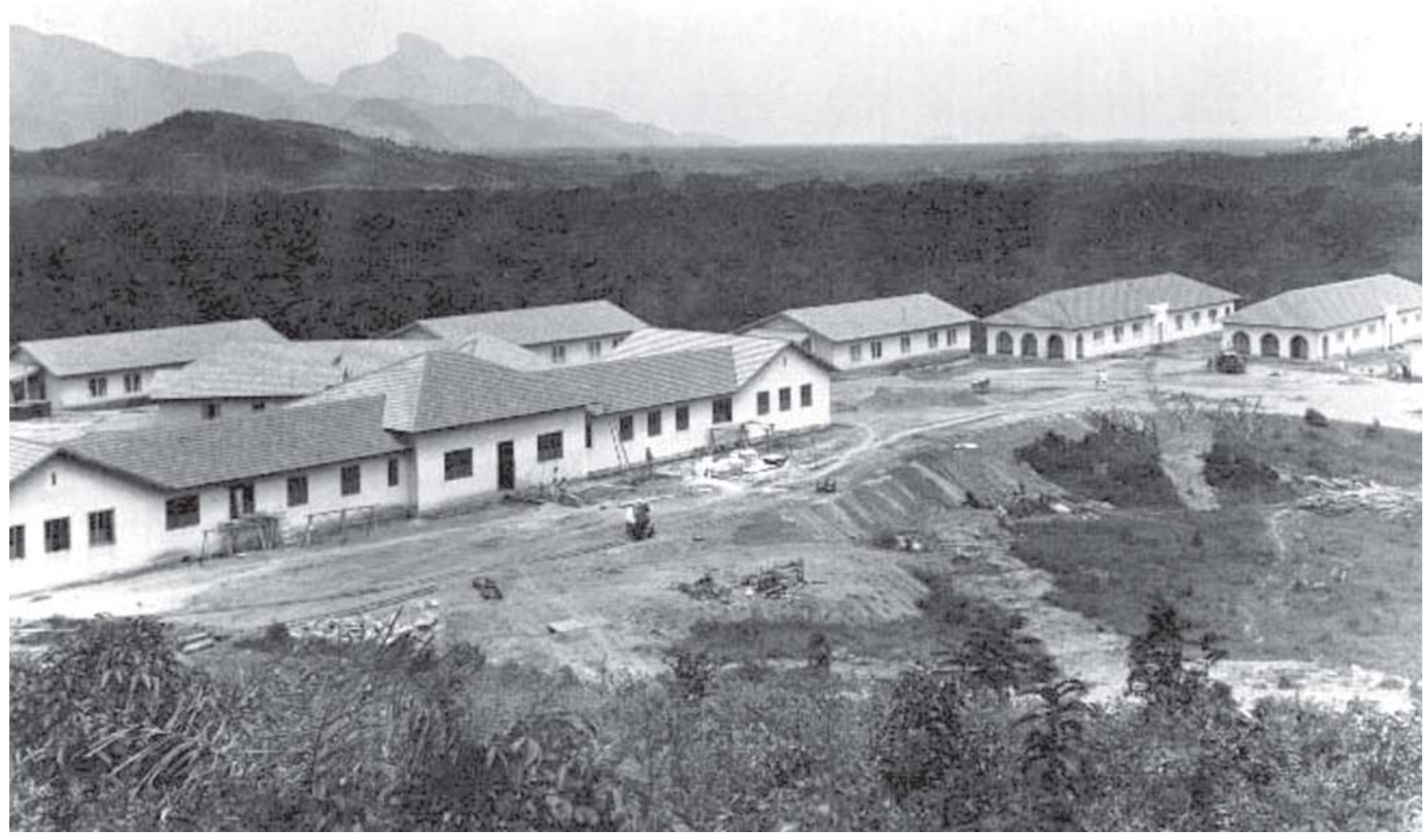

Figura 1: Aspecto de um conjunto de pavilhões da Colônia Juliano Moreira. Fundo Gustavo Capanema. (Centro de Pesquisa e Documentação de História Contemporânea do Brasil/Fundação Getulio Vargas - CPDOC/FGV) 
Cabe nos determos um pouco no trabalho de Ramos de Azevedo, para entendermos o sistema de pavilhões na constituição da estrutura física da Colônia Juliano Moreira. Formado na Bélgica, esse engenheiro-arquiteto foi um dos adeptos, no Brasil, do sistema Tollet de arquitetura hospitalar. Desenvolvido em 1872, o sistema propunha que as construções hospitalares ficassem afastadas das aglomerações urbanas e localizadas em terrenos ensolarados. A superfície do terreno deveria aumentar na proporção do aumento do número de alojamentos coletivos. Os edifícios seriam dispostos por toda a superfície do terreno e respeitariam um paralelismo entre os diversos prédios, entre outros itens de segurança. O sistema assim concebido foi amplamente difundido por toda a Europa. Ficou conhecido como modelo pavilhonar e foi marcado pelo medo do contágio pelos germes seguindo as descobertas de Louis Pasteur. Era caracterizado por edifícios de, no máximo, dois pavimentos. Neles imperava o princípio de isolamento, onde cada doença e cada doente eram isolados, no interior de diferentes pavilhões (Tollet, 1894).

Durante seus estudos na Bélgica, Ramos de Azevedo teve contato com hospitais franceses construídos, ou em construção, de acordo com o sistema Tollet, como o Hospital Bichat, de Paris, e os hospitais de Saint-Denis, Le Havre, Eperney, Bourges, Le Mans e Montpellier, mas sobretudo como o de Antuérpia, localizado na Bélgica e construído entre 1878 e 1880 (Mignot, 1983, p.229).

Em termos de modelos de hospitais de isolamento, o do Instituto Pasteur de Paris tornou-se referência. Erguido em 1900, próximo aos laboratórios de pesquisa do instituto parisiense, o Hospital Pasteur foi, por quarenta anos, um dos principais modelos de hospital de isolamento no mundo: a "não infecção se revelaria o primeiro princípio do hospital, cuja arquitetura estava submetida à absoluta necessidade de isolamento, desinfecção e redução do mobiliário hospitalar ao mínimo" (Opinel, 2007, p.97; grifo meu).

O cientista Oswaldo Cruz, à semelhança do instituto parisiense, mandou também construir um hospital em Manguinhos durante seus últimos anos de vida, entre $1912 \mathrm{e}$ 1917, seguindo as recomendações de um hospital higiênico: amplas varandas, pé-direito alto e sistema de refrigeração que facilitavam a aeração e conferiam mais conforto aos quartos. O programa norteador foi a bacteriologia preconizada por Pasteur, que combatia cada doença em separado, ou seja, em cada pavilhão. Embora tenha sido construído um só pavilhão, seu projeto original previa a construção de outros cinco. No estudo de Benchimol (1990) sobre o construtor de Manguinhos, observa-se que seus primeiros projetos hospitalares incorporaram às antigas regras da arquitetura higienista, de finais do século XVIII, e da arquitetura pavilhonar, de finais do século XIX, o saber e as tecnologias médicas oriundas da revolução pasteuriana.

No caso da Colônia Juliano Moreira, a expansão da assistência psiquiátrica, na década de 1940, foi associada ao formato do hospital-colônia nos moldes de complexo hospitalar. Ao mesmo tempo que surgiam novos núcleos ainda dentro do sistema pavilhonar, já se adotava a tipologia arquitetônica que se consolidaria nessa década e na seguinte no Brasil para os espaços de saúde, qual seja, a do bloco único (ou monobloco). Lembremo-nos de que a década de 1930 foi marcada por uma política centralizadora, liderada pelo presidente Getúlio Vargas. Ainda que não caibam correlações simplistas - sobretudo ao considerarmos que estudos recentes indicam a ocorrência, no período, de uma centralização normativa e 
uma descentralização executiva (Fonseca, 2007) - foi nessa época que se afirmou uma estrutura hospitalar que concentrava, em apenas uma edificação, diversos tratamentos e doenças.

\section{O modelo do bloco único vertical}

No começo do século XX, o sistema monobloco, criado nos EUA, atraía cada vez mais planejadores hospitalares e parecia ser a resposta a uma modernidade mais própria ao novo século. Segundo Pevsner (1997, p.158), "a mudança pode ser também descrita ... como da passagem do período pré-antisséptico para o antisséptico. ... Se a bacteriologia estava certa, a necessidade dos pavilhões tinha acabado. Ochsner e Sturm teriam escrito em 1907 que o pavilhão 'não pode mais ser usado como base para a construção hospitalar' e que a nova tendência era o 'edifício compacto de vários andares'". As vantagens do monobloco - quanto mais alto melhor -, ainda segundo Pevsner (p.158), "repousa na preservação da circulação do pessoal de serviço e nos dutos, isto é, calefação, iluminação, limpeza e muito mais". Durante as primeiras décadas do novo século, o pavilhonar ainda seria adotado, mas praticamente restrito a instituições regidas pela concepção de colônia, para tratamento de pacientes cujas doenças requeriam isolamento, como a tuberculose, a lepra e as doenças de origem mental.

Ernesto de Sousa Campos (1882-1970), médico, engenheiro, autor de diversos projetos hospitalares no Brasil e ministro da Saúde em 1946, foi um dos maiores defensores do modelo monobloco. Chamado para supervisionar a elaboração de um novo projeto para o Hospital das Clínicas da Faculdade de Medicina de São Paulo, Sousa Campos percorreu diversos hospitais, durante viagem de seis meses pelos EUA e Europa em 1925, com o intuito de transformar a proposta inicial, defendida por Ramos de Azevedo - pavilhonar e de feições neogóticas -, em outra que contemplasse a nova orientação formal que chegava ao Brasil por meio da atuação da Fundação Rockefeller.

A atuação dessa entidade, no Brasil, resultou, entre outras edificações, a da sua sede no Rio de Janeiro, instalada nas proximidades do então Instituto Oswaldo Cruz, onde Sousa Campos atuou como técnico (Figura 2).

Para Sousa Campos, a primeira questão para resolver era

decidir se a escola seria dispersa em pavilhões ou obedeceria ao tipo concentrado. Do exame da questão resultou a preferência pelo sistema centralizado, em franca vitória nas organizações modernas da América do Norte. ... um monobloco era ousadia para São Paulo naqueles tempos. ... Em 1926-1928, o tipo dominante era o hospital-jardim, com pavilhões isolados. ... Mas, depois de nossa observação através da Europa e América, a balança pendeu, todavia, decididamente para o monobloco (Campos, 1944, p.58).

O projeto vitorioso seria o mesmo utilizado para o Hospital das Clínicas de Salvador, de autoria de Sousa Campos e Hipólito Pujol Jr. (Figura 3).

O texto de Márcia Monteiro (2011) nos apresenta os 'hospitais do açúcar' e traz importantes contribuições para o estudo sobre a transposição de um modelo a outro. Há conhecimento de hospitais construídos na era Vargas para tuberculosos, doentes mentais, leprosos, entre outros, mas eram praticamente desconhecidos até então os hospitais 
construídos para trabalhadores das plantações de cana-de-açúcar. Monteiro inicia seu texto com uma radiografia das condições de vida desses trabalhadores nos estados de Pernambuco, Bahia, Minas Gerais, Sergipe, Alagoas, Rio de Janeiro e São Paulo. A autora analisa a mão de obra que atuava nos centros de saúde para esses trabalhadores. Em algumas das usinas, os enfermeiros eram pagos por companhias de seguros e em algumas outras havia a figura do farmacêutico. Mas é na análise dos projetos que desejo deter-me.

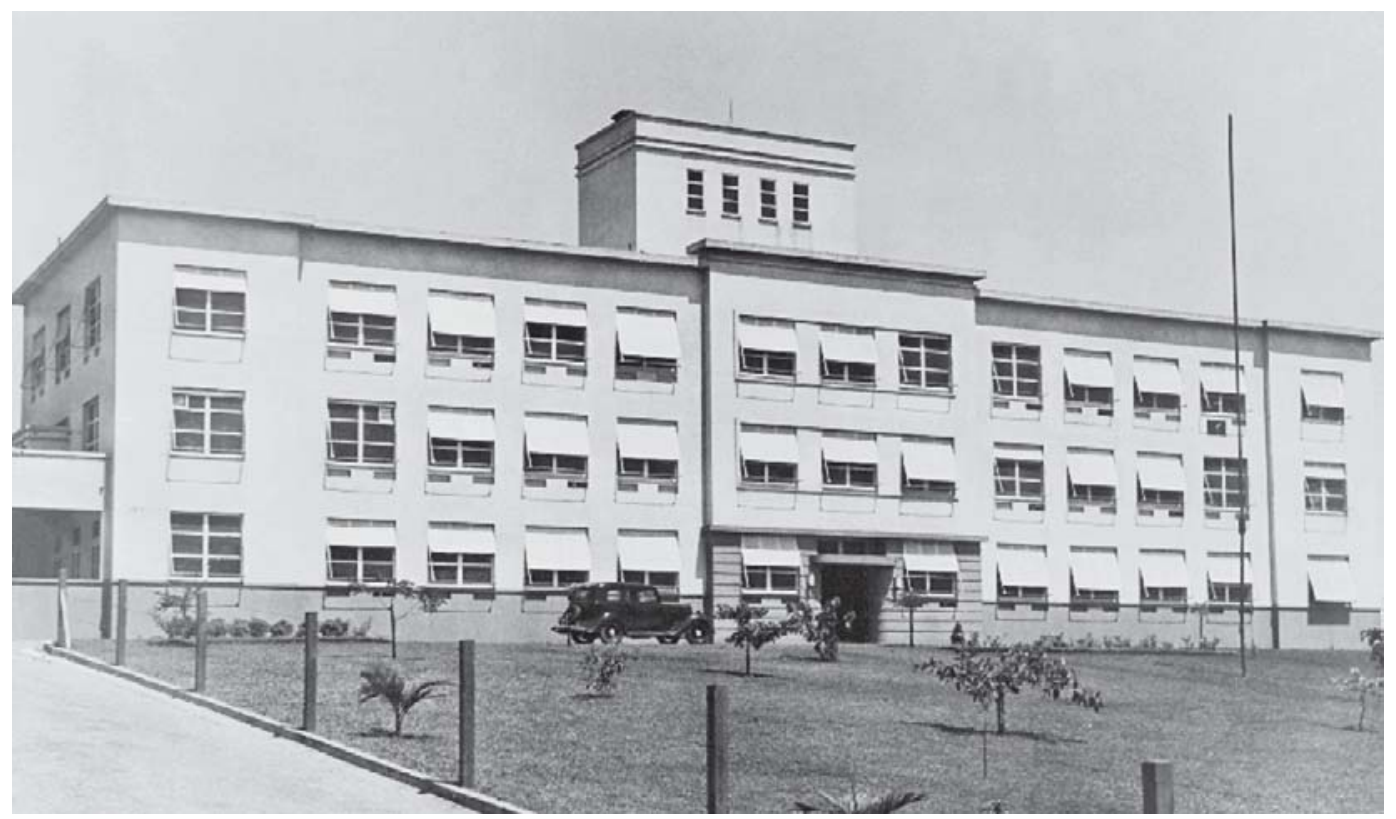

Figura 2: Imagem da fachada do recém-inaugurado edifício-sede da Fundação Rockefeller em Manguinhos, c.1937 (Casa de Oswaldo Cruz/Fiocruz)
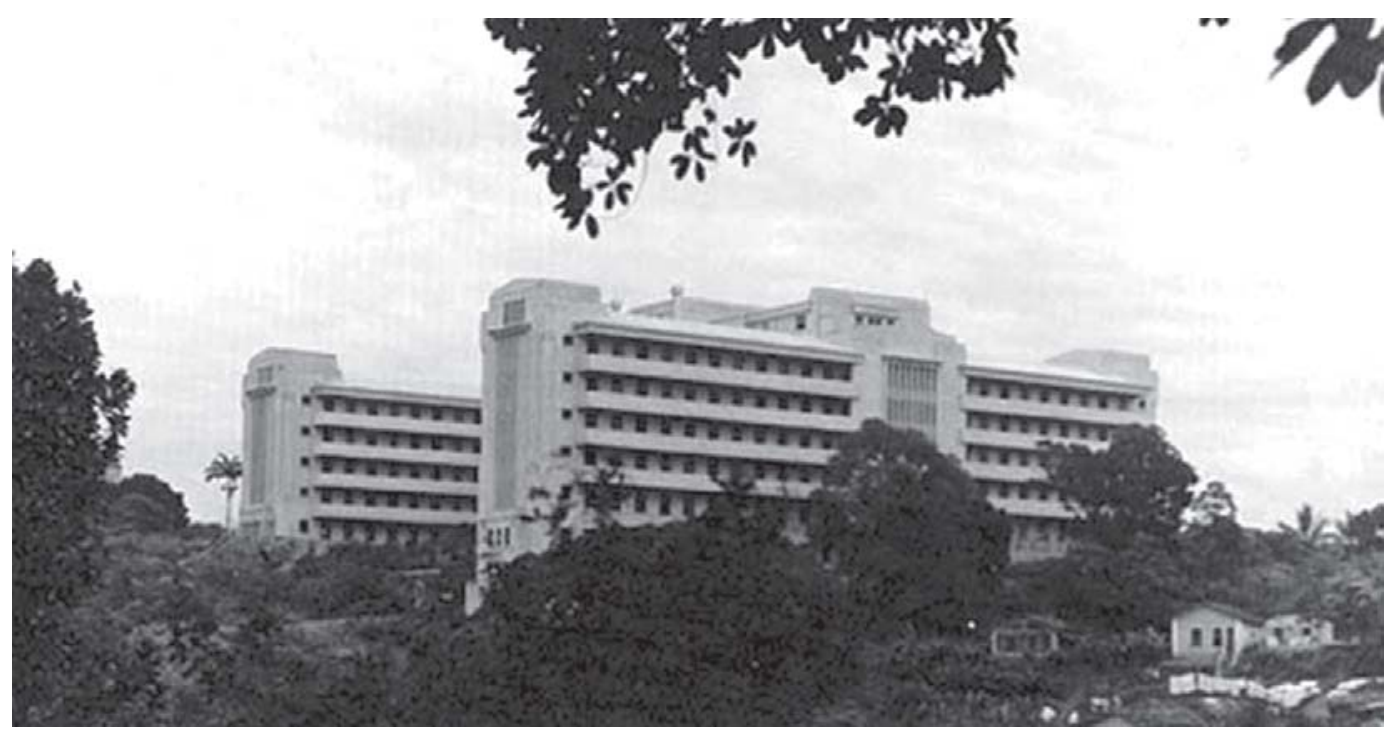

Figura 3: Vista do Hospital das Clínicas de Salvador, construído entre 1938 e 1943. Fundo Gustavo Capanema (CPDOC/FGV) 
O Ministério da Educação e Saúde, mesmo depois do desmembramento das duas áreas, em 1953, mantinha em seus quadros arquitetos, desenhistas e engenheiros que realizavam projetos hospitalares para todo o Brasil e para todas as instituições a ele subordinadas, o que certamente incluía as usinas e seus hospitais. Tais profissionais procuravam adotar formas construtivas que pudessem atender a um mínimo de padronização, visando à economia de recursos. Felizmente - a meu ver -, alguns projetos fugiram dessa recomendação e foram desenvolvidos dentro de uma moderna concepção espacial, fazendo surgir criações que merecem estudos mais aprofundados, dada a qualidade de sua arquitetura. $\mathrm{O}$ trabalho de Monteiro (2011) avança na análise dos hospitais do açúcar, com uma boa abordagem arquitetural.

A autora apresenta a relação de unidades construídas e seus ambulatórios pelos estados açucareiros. A solução apontava para a construção de ambulatórios em locais diversos, padronizando processos e materiais a fim de superar, nesse caso, a escassez de mão de obra e reduzir os custos de manutenção. Nesse sentido, a Seção de Assistência à Produção, do Ministério, estabeleceu protótipos para ambulatórios-padrão em três tipos, seguindo a curiosa recomendação formal e estética do "critério funcional corbusiano, com estilo rural brasileiro" (Monteiro, 2011).

O Serviço Técnico Industrial do Instituto do Açúcar e do Álcool, por sua vez, propunha projetos de tipologias distintas e programas básicos adaptados à realidade local, o que indica uma certa resistência a se submeter a uma padronização, que, entretanto, era seguido por outras equipes. Tais tipologias obedeciam, de acordo com Monteiro (2011), recomendações da publicação Padrões mínimos de hospitais, da década de 1950 a que fazia duas indicações para a arquitetura dessas instalações: aquela elaborada sob o critério funcionalista corbusiano e mesclado ao rural brasileiro, proposta por José Oliveira Leite; e a edificação urbana com traços da arquitetura funcionalista de Hamilton Fernandes.

Buscava-se, assim, uma construção de linhas modernas, modesta e duradoura, em lugar do "luxo de duração efêmera" (Monteiro, 2011), que podemos associar, por exemplo, às fachadas dos hospitais das beneficências portuguesas. ${ }^{4}$ A tipologia baseava-se na ideia de construir hospitais no "sistema padrão-progressivo-flexível", segundo podemos apreender do estudo de Monteiro: construção de racionalidade e sistema de construção pré-fabricada, com solução funcionalista de princípios corbusianos - ênfase na utilidade do edifício e da técnica -, respondendo às exigências mecânicas da sociedade industrial e as de construção padronizada e anônima.

Esses princípios iam ao encontro das recomendações do Ministério da Educação e Saúde nos casos de construções voltadas para o combate à tuberculose: "estudo e padronização da construção de sanatórios e dispensários tipo campanha, eficiente, de baixo custo e manutenção econômica, porém sem sacrifícios de suas qualidades técnicas e funcionais" (Ribeiro, 1956, p.185). Na prática, porém, tais recomendações resultaram em propostas arquitetônicas distintas, de acordo com a opção construtiva adotada pelo arquiteto responsável pelo projeto.

O projeto desenvolvido por Bernardes para o Sanatório de Tuberculosos de Curicica, no Rio de Janeiro, por exemplo, seguiu as indicações técnicas do Serviço Nacional Contra a Tuberculose. Sua arquitetura privilegiou as linhas funcionalistas e racionais recomendadas, 
mas sem abandonar o sistema pavilhonar, ainda que naqueles finais da década de 1940 ele já estivesse em desuso. Sua opção pelo sistema em pavilhões atendia ao tratamento da tuberculose pulmonar, que exigia áreas livres e verdes e o aproveitamento dos ventos, mais que a exposição ao sol.

No Sanatório do Sancho ou Sanatório Popular do Recife (atual Hospital Otávio de Freitas), que já possuía sanatório próprio para o tratamento da tuberculose óssea - um monobloco vertical avarandado, de tipologia semelhante a diversos outros erguidos no Brasil entre 1937 e 1945 -, procurou-se seguir as indicações do Ministério (Bittencourt, 2000) no projeto de ampliação a cargo de Sérgio Bernardes, para oferecer tratamento à tuberculose pulmonar. O projeto seguiu à risca a padronização, e o arquiteto repetiu as linhas formais do Sanatório de Curicica. Por sua vez, o primeiro sanatório adotava projeto igual ao de Maracanaú, em Fortaleza (CE), construído entre 1938 e 1946.

A opção pelos grandes hospitais, caso de Pernambuco e Alagoas, implicava construí-los nos grandes centros urbanos, e não por acaso a solução centralizada de assistência ao trabalhador concentrada nessas capitais fez surgirem os monoblocos de acentuada verticalidade. Tais hospitais apresentavam uma estética que não podemos associar ao movimento

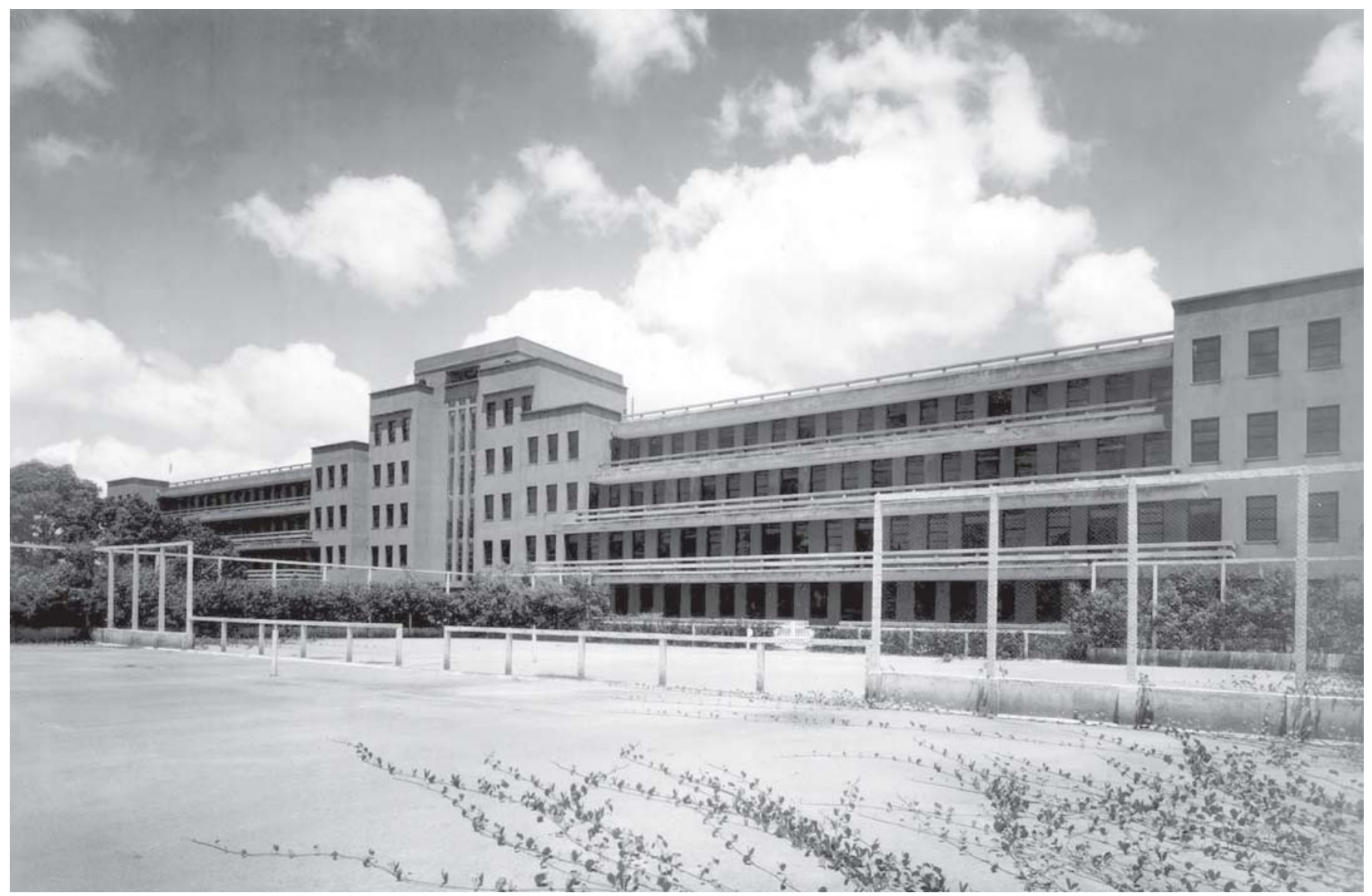

Figura 4: Vista do Sanatório do Sancho, em Recife. Fundo Gustavo Capanema (CPDOC/FGV) 
entendido pela historiografia da arquitetura brasileira como modernista, qual seja, a defendida por Le Corbusier e seus seguidores, de caráter racional e funcional, que marcaria a produção nacional e toda uma escola de arquitetos, como Oscar Niemeyer, Rino Levi, Sérgio Bernardes e Affonso Eduardo Reidy.

Essa 'tipologia' procurou abandonar as desvantagens da adoção de um sistema em pavilhões (especialmente por demandar grandes terrenos arborizados em meio às malhas urbanas das metrópoles, que se adensavam cada vez mais), e aliar as práticas ainda vantajosas (aeração, ventilação, insolação) às das construções compactas, como podemos ver nas linhas do Sanatório do Sancho. De qualquer forma, deve ser entendida como um modelo de transição, antes da consolidação do hospital em bloco único ou como um complexo de blocos, que alcançaria a hegemonia depois da década de 1950, em parte devido à grande dedicação dos arquitetos a projetos que passariam a empregar cada vez mais a alta tecnologia.

Um dos arquitetos dos hospitais do açúcar, Germano Galler, foi aluno do Curso de Planejamento de Hospitais oferecido pelo departamento paulista do Instituto de Arquitetos do Brasil em abril de 1953, curso que representa um turning point nacional nesse processo. A equipe de professores era composta por grandes autores de projetos hospitalares, como Rino Levi, Jarbas Karman, Jorge Machado Moreira, Roberto Cerqueira César e Oscar Valdetaro. O curso contava também com a participação de médicos, que atuavam cada vez mais na concepção do projeto hospitalar não como coautores, como já ocorrera em certos casos, mas como consultores. Entre os alunos, encontravam-se outros projetistas de hospitais, profissionais ou estudantes, como Paulo Antunes Ribeiro, autor do projeto da Maternidade Arnaldo de Moraes, no Rio de Janeiro; Aldary Toledo, na época arquiteto do Instituto de Aposentadoria e Pensões dos Bancários; Armando Mesquita, da Divisão de Obras do Ministério da Educação e Saúde; João Filgueiras Lima, estudante de arquitetura na época e futuro autor dos hospitais da Rede Sarah; e Germano Galler (IAB, 1954). Os objetivos do curso eram, entre outros, "divulgar conquistas no campo de planejamento de hospitais, analisar os elementos essenciais a um projeto são e científico, possibilitar a construção de hospitais eficientes ..., aproximar interessados, e estimular, o intercâmbio de informações e pesquisa ... (IAB, 1954, p.13, 14). Porém, mais do que isso, o curso mostrou um amadurecimento do projeto arquitetônico em meados do século $\mathrm{XX}$, ao buscar romper com o que vinha sendo realizado até então.

\section{Considerações finais}

Este artigo procurou, a partir de pesquisas recentes sobre o tema da assistência hospitalar, extrair elementos próprios à discussão sobre a arquitetura desses espaços. Da Bahia tivemos o hospital do tipo claustro e relacionado às atividades das santas casas; na Colônia Juliano Moreira, no Rio de Janeiro, predominaram os pavilhões de isolamento; e o monobloco vertical aparece como solução arquitetônica para os hospitais urbanos construídos durante a era Vargas, entre eles os hospitais do açúcar. As linhas de inspiração art déco desses hospitais, que representam modernidade mesmo que de referência, permitem classificá-los como monoblocos de transição, embora toda classificação aleatória seja passível de ampla discussão. 
Também destacam-se, aqui, atores importantes da história da arquitetura hospitalar no Brasil. Os nomes de Luiz Moraes Jr., Ramos de Azevedo, A. Porto D’Ave, Ernesto de Sousa Campos, os arquitetos e engenheiros da Divisão de Obras do Ministério da Educação e Saúde, Oscar Niemeyer, Rino Levi, Sérgio Bernardes, Roberto Nadalutti, entre tantos outros, devem sem dúvida ser considerados no desenvolvimento de pesquisas sobre o assunto.

\section{NOTAS}

* Este artigo resulta de reflexões decorrentes da análise dos textos apresentados na mesa-redonda Instituições, Arquitetura e Assistência, no seminário Estado, Filantropia e Assistência, realizado pela Casa de Oswaldo Cruz/Fundação Oswaldo Cruz, Universidade Federal Fluminense (UFF) e pelo Centro Federal de Educação Tecnológica Celso Suckow da Fonseca (Cefet-RJ), no Rio de Janeiro, em 2009.

${ }^{1}$ International Committee for Documentation and Conservation of Buildings, Sites and Neighborhoods of the Modern Movement, com representações em diversos países, o Brasil entre eles.

${ }^{2}$ Nesta e nas demais citações de textos em outros idiomas a tradução é livre.

${ }^{3}$ Pevsner (1997) e Mignot (1983) relatam alguns desses planos, projetos e inquéritos, dos quais sobressaem os de Tenon, Howard, Hunczovsky, Bernard Poyet, Le Roy etc.

${ }^{4}$ Sobre os hospitais construídos pela Beneficência Portuguesa do Rio Grande do Sul, Larissa Chaves (2009) analisa a relação entre sua arquitetura e a identidade portuguesa. A autora afirma que todos os edifícios das beneficências apresentam semelhanças bem marcantes, representadas pela escolha do estilo eclético e pela ostentação - características essenciais para materializar os desejos dos imigrantes portugueses de fazer parte de um grupo de elite.

\section{REFERÊNCIAS}

BARRETO, Maria Renilda N.

Hospital São Cristóvão. In: Barreto, Maria Renilda N.; Souza, Christiane Maria Cruz (Coord.). História da saúde na Bahia: instituições e patrimônio arquitetônico,1808-1958. Rio de Janeiro: Editora Fiocruz. 2011.

BENCHIMOL, Jaime Larry (Coord.). Manguinhos do sonho à vida: a ciência na Belle Époque. Rio de Janeiro: Casa de Oswaldo Cruz. 1990.

BITENCOURT, Fábio (Org.).

Arquitetura do Instituto Vital Brazil: um patrimônio modernista da saúde. Rio de Janeiro: Rio Books. 2009.

BITENCOURT, Fábio (Org.).

Hospital dos Servidores do Estado: um patrimônio de saúde, arquitetura e história. Rio de Janeiro: HSE. 2007.

BITTENCOURT, Tania Maria Mota.

Peste Branca - arquitetura branca: os sanatórios de tuberculose no Brasil na primeira metade do século vinte. Dissertação (Mestrado) - Escola de Engenharia de São Carlos, Universidade de São Paulo, São Carlos. 2000.

CAMPOS, Ernesto de Souza.

Historia do Hospital das Clinicas da Faculdade de Medicina de São Paulo. Revista Médica Social, São Paulo, v.2, n.17, p.55-58. 1944.
CHAVES, Larissa.

Apresentação da identidade portuguesa: os edifícios históricos das sociedades de Beneficência do Rio Grande do Sul. Trabalho apresentado no Seminário Internacional Estado, Filantropia e Assistência. Rio de Janeiro. 2009.

CREMNITZER, Jean-Bernard. Architecture et santé: les temps du sanatorium en France et Europe. Paris: Éditions A. et J. Picard. 2005.

CREMNITZER, Jean-Bernard; TOULIER, Bernard (Ed.).

Histoire et réhabilitation des sanatoriums en Europe. Paris: Docomomo. 2004.

FONSECA, Cristina.

Saúde no governo Vargas (1930-1945): dualidade institucional de um bem público. Rio de Janeiro: Editora Fiocruz. 2007.

FOUCAULT, Michel.

Microfisica do poder. Rio de Janeiro: Graal. 1979.

FOUCAULT, Michel et al.

Les machines à guérir: aux origines de l’hôpital moderne. Liège: Pierre Mardaga. 1979.

IAB.

Instituto de Arquitetos do Brasil.

Departamento de São Paulo. Comissão de 
Planejamento de Hospitais. Planejamento de hospitais. São Paulo: Instituto de Arquitetos do Brasil. 1954.

MIGNOT, Claude.

Architecture of the 19th century. Cologne: Evergreen. 1983.

MIQUELIN, Lauro Carlos.

Anatomia dos edifícios hospitalares. São Paulo: Cedas. 1992.

MONTEIRO, Márcia Rocha.

Homens da cana e hospitais do açúcar: uma arquitetura da saúde no Estado Novo. História, Ciências, Saúde - Manguinhos, Rio de Janeiro, v.18, supl.1, p.67-94. 2011.

OPINEL, Annick.

The Pasteur hospital as an element of Emile Roux's anti-diphteria apparatus (1890-1914). Dynamis, Granada, n.27, p.83-106. 2007.

PEVSNER, Nikolaus.

A history of building types. Princeton: Princeton University Press. 1997.

PÔRTO, Ângela et al.

História da saúde no Rio de Janeiro: instituições e patrimônio arquitetônico - Rio de Janeiro (1808-1958). Rio de Janeiro: Editora Fiocruz. 2008.

RIBEIRO, Leonídio.

A luta contra a tuberculose no Brasil: apontamentos para a sua história. Rio de Janeiro: Editorial Sul-Americana. 1956.

SANGLARD, Gisele; COSTA, Renato Gama-Rosa. Direções e traçados da assistência hospitalar no
Rio de Janeiro, 1923-1931. História, Ciências, Saúde - Manguinhos, Rio de Janeiro, v.11, n.1, p.107-141. 2004.

TOLEDO, Luis Carlos.

Feitos para cuidar: a arquitetura como um gesto médico e a humanização do edifício hospitalar. Tese (Doutorado) - Faculdade de Arquitetura e Urbanismo, Universidade Federal do Rio de Janeiro, Rio de Janeiro. 2008.

TOLEDO, Luis Carlos.

Feitos para curar: arquitetura hospitalar e processo projetual no Brasil. Rio de Janeiro: Associação Brasileira para o Desenvolvimento do Edifício Hospitalar. 2006.

\section{TOLLET, Casimir.}

Les hôpitaux modernes au XIXe siècle: description plus récemment édifiés, divisés en dix sections par contrées, études comparatives sur leurs principales conditions d'établissement. Paris: s.n. 1894.

VENÂNCIO, Ana Teresa A.

Da colônia agrícola ao hospital-colônia: configurações para a assistência psiquiátrica no Brasil na primeira metade do século XX. História, Ciência, Saúde - Manguinhos, Rio de Janeiro, v.18, supl.1, p.35-52. 2011.

WEBER, Beatriz Teixeira; SERRES, Juliana C. Primon.

Instituições de saúde de Porto Alegre: inventário. Porto Alegre: Ideograf. 2008.

WOLFF de CARVALHO, Maria Cristina.

Ramos de Azevedo. São Paulo: Edusp. 200. 